\title{
Oxygen Uptake, Ventilation, and Symptoms During Low-Frequency Versus High-Frequency NMES in COPD: A Pilot Study.
}

Citation for published version (APA):

Sillen, M. J., Wouters, E. F. M., Franssen, F. M., Meijer, K., Stakenborg, K. H., \& Spruit, M. A. (2011). Oxygen Uptake, Ventilation, and Symptoms During Low-Frequency Versus High-Frequency NMES in COPD: A Pilot Study. Lung, 189(1), 21-26. https://doi.org/10.1007/s00408-010-9265-0

Document status and date:

Published: 01/02/2011

DOI:

10.1007/s00408-010-9265-0

Document Version:

Publisher's PDF, also known as Version of record

Document license:

Taverne

Please check the document version of this publication:

- A submitted manuscript is the version of the article upon submission and before peer-review. There can be important differences between the submitted version and the official published version of record.

People interested in the research are advised to contact the author for the final version of the publication, or visit the DOI to the publisher's website.

- The final author version and the galley proof are versions of the publication after peer review.

- The final published version features the final layout of the paper including the volume, issue and page numbers.

Link to publication

\footnotetext{
General rights rights.

- You may freely distribute the URL identifying the publication in the public portal. please follow below link for the End User Agreement:

www.umlib.nl/taverne-license

Take down policy

If you believe that this document breaches copyright please contact us at:

repository@maastrichtuniversity.nl

providing details and we will investigate your claim.
}

Copyright and moral rights for the publications made accessible in the public portal are retained by the authors and/or other copyright owners and it is a condition of accessing publications that users recognise and abide by the legal requirements associated with these

- Users may download and print one copy of any publication from the public portal for the purpose of private study or research.

- You may not further distribute the material or use it for any profit-making activity or commercial gain

If the publication is distributed under the terms of Article $25 \mathrm{fa}$ of the Dutch Copyright Act, indicated by the "Taverne" license above, 


\title{
Oxygen Uptake, Ventilation, and Symptoms During Low-Frequency Versus High-Frequency NMES in COPD: A Pilot Study
}

\author{
Maurice J. H. Sillen • Emiel F. M. Wouters • \\ Frits M. E. Franssen - Kenneth Meijer • \\ Koen H. P. Stakenborg • Martijn A. Spruit
}

Received: 15 September 2010/ Accepted: 25 October 2010/Published online: 16 November 2010

(C) Springer Science+Business Media, LLC 2010

\begin{abstract}
Transcutaneous neuromuscular electrical stimulation (NMES) involves the application of an electrical current through electrodes placed on the skin over the targeted muscles. During high-frequency NMES (HF-NMES), oxygen uptake, minute ventilation, and the degree of symptom perception (dyspnea and fatigue) have been shown to be acceptable in chronic obstructive pulmonary disease (COPD). Currently, oxygen uptake and ventilation load have never been assessed during low-frequency NMES (LF-NMES) of the lower-limb muscles. The purpose of this study was to compare prospectively oxygen uptake, ventilation, and symptom perception during a single session of LF-NMES versus a single session of HF-NMES of quadriceps muscles in patients with COPD. In 17 COPD patients (mean $\mathrm{FEV}_{1}=45 \%$ predicted, mean body mass index $=26.2 \mathrm{~kg} / \mathrm{m}^{2}$ ), peak exercise capacity,
\end{abstract}

M. J. H. Sillen $(\bowtie)$ · F. M. E. Franssen - M. A. Spruit

Program Development Centre, Ciro+, Hornerheide 1,

Horn, The Netherlands

e-mail: mauricesillen@ciro-horn.nl

E. F. M. Wouters

Ciro+, Horn, The Netherlands

E. F. M. Wouters

Department of Respiratory Medicine, Maastricht University

Medical Centre (MUMC+), Maastricht, The Netherlands

K. Meijer

Department of Human Movement Science, School for Nutrition,

Toxicology and Metabolism of Maastricht, University Medical

Centre (MUMC+), Maastricht University, Maastricht,

The Netherlands

K. H. P. Stakenborg

Department of Biometrics, Ciro+, Horn, The Netherlands functional exercise capacity, and the Medical Research Council dyspnea grade were evaluated. In addition, oxygen uptake, minute ventilation, heart rate, and Borg symptom scores were assessed during one session of LF-NMES $(15 \mathrm{~Hz})$ and one session of HF-NMES $(75 \mathrm{~Hz})$ and compared with peak values. Mean oxygen uptake (LF-NMES: $327 \mathrm{ml} / \mathrm{min}$ vs. HF-NMES: $315 \mathrm{ml} / \mathrm{min}$ ), minute ventilation (LF-NMES: $14 \mathrm{~L}$ vs. HF-NMES: $15 \mathrm{~L}$ ), and heart rate (LF-NMES: 86 BPM vs. HF-NMES: 83 BPM) were similar during both NMES frequencies. Patients used a relatively low proportion of their peak aerobic capacity during both NMES sessions (LF-NMES: $34 \%$ vs. HF-NMES: 33\%; $P=0.397)$. In addition, symptom Borg scores for dyspnea and leg fatigue were also comparable. Oxygen uptake, ventilation, and symptoms of dyspnea and fatigue were comparable and tolerable during LF-NMES and HF-NMES in patients with COPD. Therefore, LF-NMES and HF-NMES may both be suitable rehabilitative modalities to be used in severely dyspneic patients with lower-limb muscle dysfunction.

Keywords Chronic obstructive pulmonary disease . Neuromuscular electrical stimulation - Oxygen uptake . Ventilation

$\begin{array}{ll}\text { Abbreviations } \\ \text { BMI } & \text { Body mass index } \\ \text { BPM } & \text { Beats per minute } \\ \text { COPD } & \text { Chronic obstructive pulmonary disease } \\ \text { CPET } & \text { Cardiopulmonary exercise test } \\ \text { DL }_{\mathrm{CO}} & \begin{array}{l}\text { Diffusion capacity of the lung for carbon } \\ \end{array} \\ \text { meV } & \text { Fonoxide } \\ \text { FFMI } & \text { Fat-free mass index }\end{array}$




\begin{tabular}{|c|c|}
\hline HF-NMES & $\begin{array}{l}\text { High-frequency transcutaneous } \\
\text { neuromuscular electrical stimulation }\end{array}$ \\
\hline IQR & Interquartile range \\
\hline LF-NMES & $\begin{array}{l}\text { Low-frequency transcutaneous } \\
\text { neuromuscular electrical stimulation }\end{array}$ \\
\hline MRC & Medical Research Council dyspnea scale \\
\hline MVV & $\begin{array}{l}\text { Maximal voluntary ventilation } \\
\left(\mathrm{MVV}=40 * \mathrm{FEV}_{1}\right)\end{array}$ \\
\hline$\%$ MVV & Percentage maximal voluntary ventilation \\
\hline 6MWD & Distance achieved by the 6-min walking test \\
\hline NMES & $\begin{array}{l}\text { Transcutaneous neuromuscular electrical } \\
\text { stimulation }\end{array}$ \\
\hline Peak HR & Peak heart rate \\
\hline Peak VE & Peak minute ventilation (in liters, L) \\
\hline Peak $\mathrm{VO}_{2}$ & Peak oxygen uptake (in $\mathrm{ml} / \mathrm{min}$ ) \\
\hline & Percentage predicted value \\
\hline VC max & Maximum vital capacity \\
\hline
\end{tabular}

\section{Introduction}

Lower-limb skeletal muscle dysfunction (e.g., quadriceps weakness and/or loss of quadriceps muscle endurance) is a common extrapulmonary manifestation of chronic obstructive pulmonary disease (COPD) [1-3] and contributes to a poor exercise performance, increased use of health care, and mortality in COPD patients [4-6]. Daily physical inactivity partially determines skeletal muscle dysfunction in COPD [7]. Therefore, these patients have a clear indication for pulmonary rehabilitation $[8,9]$.

Exercise-based rehabilitation programs are able to improve lower-limb muscle strength and endurance, functional exercise performance, and health status in patients with COPD $[10,11]$. Exercise training programs typically consist of lower-limb endurance/interval training, resistance training, or a combination thereof $[12,13]$. Unfortunately, the benefits of these lower-limb endurance exercises (e.g., treadmill walking and/or stationary ergometry cycling) may be limited in COPD patients due to exercise-induced dyspnea and ventilatory limitation during training [14]. Indeed, aerobic exercise training can result in high values of oxygen uptake and ventilation, which exact a relatively high claim on the peak aerobic capacity of patients with COPD [14]. Therefore, there is great interest in new and effective alternative rehabilitative modalities that do not evoke dyspnea, such as high-intensity resistance training and transcutaneous neuromuscular electrical stimulation (NMES) [14, 15].

NMES involves the application of an electrical current through electrodes placed on the skin over the targeted muscles, thereby depolarizing motor endplates and, in turn, inducing skeletal muscle contractions [16, 17]. In patients with chronic heart failure, low-frequency NMES (LF-NMES, $<50 \mathrm{~Hz}$ ) increased muscle endurance [18], whereas high-frequency NMES (HF-NMES, $\geq 50 \mathrm{~Hz}$ ) increased muscle strength [19]. To date, it remains unknown which stimulation frequency leads to better gains in muscle strength and endurance and which stimulation protocol is optimal for patients with COPD. Indeed, the effects of LF-NMES are unknown in COPD. Nevertheless, due to the striking similarities in systemic factors that contribute to exercise intolerance in patients with COPD or chronic heart failure [20], a reduced fiber type I proportion [21], and loss of muscle endurance in COPD [1, 22], it seems reasonable to hypothesize that LF-NMES will also have positive effects on quadriceps muscle endurance and functional exercise capacity in COPD.

Recently, oxygen uptake, minute ventilation, and the degree of symptom perception (dyspnea and fatigue) have been shown to be acceptable during a single session of HF-NMES in patients with COPD [15]. During LF-NMES, the authors expect also a relatively low and acceptable oxygen uptake and ventilation, which is comparable to those during HF-NMES [15]. Currently, this has never been studied but seems a necessary step prior to a randomized controlled trial in which the effects of NMES (LF vs. HF) on lower-limb muscle dysfunction are assessed in COPD.

The purpose of this study was to compare prospectively oxygen uptake, ventilation, and symptom perception during a single session of LF-NMES and a single session of HF-NMES of the quadriceps muscles in patients with COPD. In addition, safety was assessed by monitoring adverse events.

\section{Methods}

\section{Study Subjects}

Seventeen patients (10 men) with clinically stable COPD [23] were recruited at the start of a comprehensive pulmonary rehabilitation program at Ciro+ in Horn (the Netherlands) [9]. Patients were considered ineligible to participate if they had neuromuscular disorders, metal implants in the lower limbs, a cardiac pacemaker, and/or an exacerbation of symptoms in the preceding 4 weeks. Patients with long-term oxygen therapy were excluded because of the methodology that is used to measure oxygen uptake and ventilation (e.g., Oxycon Mobile).

\section{Study Design}

This was a prospective, randomized crossover pilot study. The study protocol was approved by the Medical Ethical 
Committee of the Maastricht University Medical Centre+ (MEC 09-3-004) and conformed to the principles outlined in the World Medical Association declaration of Helsinki which was revised in Seoul. Details of the trial were registered at www.trialregister.nl (NTR1834) before subject enrolment. All patients gave written informed consent to take part in the study.

Pulmonary function, body composition (whole-body dual-energy X-ray absorptiometry), peak cycling load, peak aerobic capacity, functional exercise capacity, quadriceps muscle strength, Borg symptom scores for dyspnea and fatigue, and the Medical Research Council dyspnea grade were determined at baseline as a routine part of entry into the pulmonary rehabilitation program $[9,24]$. Coexisting morbidities were assessed using the Charlson comorbidity index (CCI) [25]. Moreover, all patients underwent a single session of LF-NMES and a single session of HF-NMES on two separate days within the same week, in random order. These sessions occurred during the first week of the rehabilitation program, $0-4$ weeks after the baseline testing. Randomization was performed by means of a computer-generated randomization list.

Safety was assessed by monitoring adverse events. Adverse events were defined as changes in health or sideeffects, such as pain and/or muscle cramps, that occurred in patients who participated in the study while receiving the treatment.

\section{Methods}

During both NMES sessions, continuous online calculations of breath-by-breath oxygen uptake $\left(\mathrm{VO}_{2}\right)$ and minute ventilation $\left(\mathrm{V}_{\mathrm{E}}\right)$ were obtained using the Oxycon Mobile, a portable metabolic system (CareFusion, San Diego, CA, USA) (Fig. 1). After calibration, the face mask (Combitox, Dräger Safety, Lübeck, Germany) was carefully adjusted to the patient's face and checked for air leaks. Data were collected breath by breath and processed using JLAB ver. $5.20 \mathrm{~b}$ software (CareFusion).

\section{NMES Protocols}

During both NMES sessions, bilateral electrical stimulation of the quadriceps muscles was applied using a portable electrical stimulator (Gymnex 4, GymnaUniphy N.V., Bilzen, Belgium). A total of eight electrodes were placed on the quadriceps femoris muscles (four on each leg): two on the vastus medialis, one on the rectus femoris muscle, and one on the vastus lateralis muscle (Fig. 1). Both stimulation protocols were preset in the devices. The stimulation protocol of LF-NMES consisted of a symmetrical biphasic square pulse at $15 \mathrm{~Hz}$, a duty cycle of $8 \mathrm{~s}$ on and $2 \mathrm{~s}$ off, a pulse time of $390 \mu \mathrm{s}$ during a session lasting

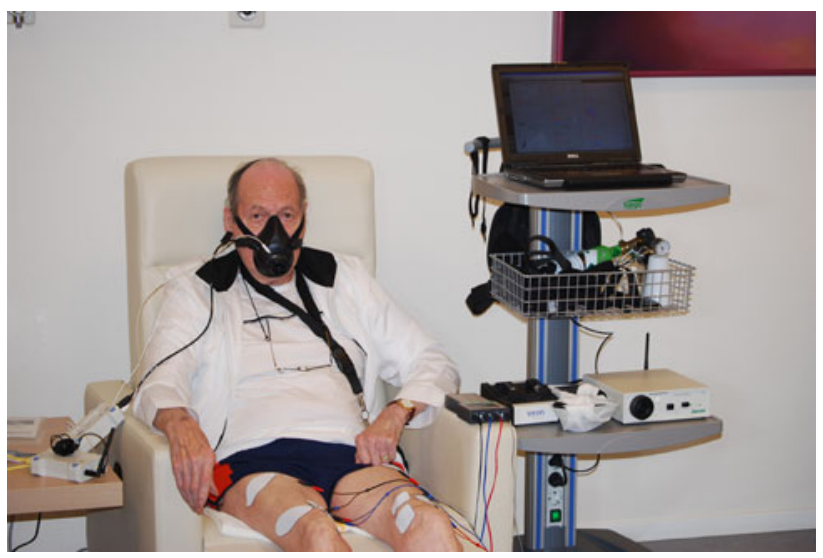

Fig. 1 Measurement of oxygen uptake and minute ventilation during a session of bilateral NMES of the quadriceps muscles in a male patient with COPD

29 min. The stimulation protocol of the HF-NMES consisted of a symmetrical biphasic square pulse at $75 \mathrm{~Hz}$, a duty cycle of $6 \mathrm{~s}$ on and $29 \mathrm{~s}$ off, a pulse time of $410 \mu \mathrm{s}$ during a session lasting $21 \mathrm{~min}$. During both sessions the intensity was increased to maximum individual toleration. The muscle contractions were visible and palpable. In addition, Borg symptom scores for dyspnea and leg fatigue were obtained before and after both NMES sessions [26].

\section{Statistical Analysis}

All statistical analyses were performed using SPSS for Windows ver. 17.0.1 (SPSS, Inc., Chicago, IL, USA). Continuous data were tested for normality and presented as mean and standard deviation or as median and interquartile range (IQR). In addition, two-tailed paired $t$ tests were used for within-group comparisons. A priori, the level of statistical significance was set at $P \leq 0.05$.

\section{Results}

\section{Characteristics}

The baseline characteristics of the patients are given in Table 1. On average, patients had moderate to severe COPD and the lungs had poor diffusing capacity for carbon monoxide (Table 1). Most patients were severely dyspneic, reporting on the MRC dyspnea scale that they had to stop for breath after walking 100 yards $(91.4 \mathrm{~m})$ or after a few minutes on the level. Moreover, patients had explicit quadriceps weakness (mean $\pm \mathrm{SD}=55 \pm 12 \%$ predicted [27]), as well as poor functional and peak exercise performance, with a mean $\pm \mathrm{SD}$ 6-min walk distance of $380 \pm 98 \mathrm{~m}$ [28], $\mathrm{VO}_{2}$ max and maximal workload during CPET of $986 \pm 260 \mathrm{ml} / \mathrm{min}$ and $60 \pm 21 \mathrm{~W}$, respectively. 
Table 1 Participant characteristics

\begin{tabular}{|c|c|}
\hline Age (years) & $67 \pm 9$ \\
\hline Body weight (kg) & $72.7 \pm 14.7$ \\
\hline BMI $\left(\mathrm{kg} / \mathrm{m}^{2}\right)$ & $26.2 \pm 4.5$ \\
\hline FFMI $\left(\mathrm{kg} / \mathrm{m}^{2}\right)$ & $17.5 \pm 2.4$ \\
\hline $\mathrm{FEV}_{1}(\%$ predicted $)$ & $45 \pm 16$ \\
\hline $\mathrm{FEV}_{1} / \mathrm{VC} \max (\%)$ & $35 \pm 8$ \\
\hline $\mathrm{DL}_{\mathrm{CO}}(\%$ predicted $)$ & $57 \pm 22$ \\
\hline MRC dyspnea (grade) & $4 \pm 1$ \\
\hline Peak torque quadriceps muscles (\% predicted) & $55 \pm 12$ \\
\hline 6MWD (m) & $380 \pm 98$ \\
\hline 6MWD (\% predicted) & $63 \pm 17$ \\
\hline Peak load CPET (W) & $60 \pm 21$ \\
\hline Peak load CPET ( $\%$ predicted) & $52 \pm 26$ \\
\hline Peak $\mathrm{VO}_{2} \mathrm{CPET}(\mathrm{ml} / \mathrm{min})$ & $986 \pm 260$ \\
\hline Peak $\mathrm{VO}_{2} \mathrm{CPET}$ ( $\%$ predicted) & $66 \pm 30$ \\
\hline Peak $\mathrm{VCO}_{2} \mathrm{CPET}(\mathrm{ml} / \mathrm{min})$ & $945 \pm 281$ \\
\hline Peak VE CPET (L) & $38 \pm 9$ \\
\hline Peak VE CPET (\% MVV) & $93 \pm 23$ \\
\hline Peak HR CPET (BPM) & $119 \pm 15$ \\
\hline Peak HR CPET ( $\%$ predicted) & $78 \pm 8$ \\
\hline Borg dyspnea CPET (points) & $8 \pm 2$ \\
\hline Borg fatigue CPET (points) & $6 \pm 2$ \\
\hline
\end{tabular}

Data are presented as mean $\pm \mathrm{SD}$

$B M I$ body mass index, FFMI fat-free mass index, $F E V_{1}$ forced expiratory volume in $1 \mathrm{~s}, V C \max$ maximum vital capacity, $D L_{C O}$ diffusion capacity of the lung for carbon monoxide, MRC Medical Research Council dyspnea scale, $6 M W D$ distance achieved by the 6-min walking test, peak load maximum workload, CPET cardiopulmonary exercise test, peak $\mathrm{VO}_{2}$ peak oxygen uptake in $\mathrm{ml} / \mathrm{min}$, peak $V E$ peak minute ventilation in liters, peak $H R$ peak heart rate, bpm beats per minute, \% pred percentage predicted value, \% MVV percentage maximal voluntary ventilation

On average, patients were ventilatory limited at the end of the cardiopulmonary exercise test, with high Borg scores for dyspnea and fatigue (Table 1).

Significant comorbidities were present in 10 of 17 (59\%) patients with COPD. Indeed, the median score on the Charlson comorbidity index was 2 (IQR $=1-2.5$ ) points. These comorbidities included coronary heart disease $(n=5)$, diabetes $(n=3)$, nonmetastatic solid malignancy $(n=2)$, peripheral artery disease $(n=2)$, chronic heart failure $(n=1)$, transient ischemic attack $(n=1)$, Bechterew's disease $(n=1)$, and/or peptic ulcer $(n=1)$. The following pulmonary maintenance medications were used by 17 COPD patients who volunteered to participate: shortacting $\beta_{2}$ agonists $(n=8)$, short-acting anticholinergics $(n=1)$, short-acting combined bronchodilators $(n=7)$, long-acting $\beta_{2}$ agonists (LABA) $(n=3)$, long-acting anticholinergics $(n=15)$, inhaled glucocorticosteroids (alone or in combination with LABA) $(n=16)$, systemic glucocorticosteroids $(n=2)$, xanthine derivatives $(n=3)$, antioxidant agents $(n=5)$, and/or leukotriene modifiers $(n=1)$.

\section{LF-NMES Versus HF-NMES}

All patients were able to complete both NMES sessions. No differences in tolerating both frequencies were reported and no adverse events occurred during either training session.

The effects of LF-NMES and HF-NMES are compared in Table 2. Mean resting and peak oxygen uptake, minute ventilation, and heart rate were not significantly different between LF-NMES and HF-NMES sessions (Table 2). Indeed, patients used a relatively low proportion of their peak aerobic capacity, measured previously during a CPET, during both NMES sessions (LF-NMES, 34\%; HFNMES, 33\%; $P=0.386$ ). Also, Borg symptom scores for dyspnea and leg fatigue were comparable for both NMES types (Table 2).

\section{Discussion}

The present pilot study is the first to assess oxygen uptake, ventilation, and symptom perception during a session of LF-NMES and a session of HF-NMES. Both NMES frequencies appear to be safe and sustainable in dyspneic COPD patients with comorbidities. Moreover, oxygen uptake, ventilation, and Borg symptom scores for dyspnea and leg fatigue were relatively low and comparable between LF-NMES and HF-NMES.

HF-NMES is a relatively new exercise modality used in the rehabilitation of (severely) disabled patients with COPD $[17,29,30]$. For example, 4-6 weeks of HF-NMES to the quadriceps muscles resulted in improved muscle strength, exercise capacity, and disease-specific quality of life in COPD patients who had an abnormal baseline body composition or who were too dyspneic to leave their home for a hospital-based outpatient pulmonary rehabilitation program [31, 32]. Indeed, HF-NMES has even resulted in faster mobilization from bed to chair in bed-bound COPD patients requiring prolonged mechanical ventilation [33]. Therefore, it seems reasonable to conclude that HF-NMES is safe, feasible, and beneficial in patients with COPD [29]. Indeed, international guidelines recommend HF-NMES in patients with severe chronic respiratory disease with extreme skeletal muscle weakness or who are bed-bound [8].

To date, the effects of LF-NMES in COPD patients have not been studied. Nevertheless, based on the combination of severe dyspnea at rest and a clear loss of lower-limb muscle endurance [1], it may be worthwhile to assess the effects of LF-NMES on the ambulation muscles of patients with COPD. The present findings provide additional rationale to assess the effects of LF-NMES in patients with 
Table 2 Low-frequency NMES versus high-frequency NMES in COPD

\begin{tabular}{|c|c|c|c|}
\hline & $\begin{array}{l}\text { Low-frequency } \\
\text { NMES }\end{array}$ & $\begin{array}{l}\text { High-frequency } \\
\text { NMES }\end{array}$ & $P$ value \\
\hline Resting $\mathrm{VO}_{2}(\mathrm{ml} / \mathrm{min})$ & $258 \pm 65$ & $238 \pm 51$ & 0.178 \\
\hline Peak $\mathrm{VO}_{2}(\mathrm{ml} / \mathrm{min})$ & $327 \pm 96$ & $315 \pm 84$ & 0.538 \\
\hline Peak $\mathrm{VO}_{2}\left(\%\right.$ peak $\left.\mathrm{VO}_{2} \mathrm{CPET}\right)$ & $34 \pm 12$ & $33 \pm 12$ & 0.386 \\
\hline Resting VE (1) & $11 \pm 2$ & $11 \pm 2$ & 0.633 \\
\hline Peak VE (l) & $14 \pm 4$ & $15 \pm 4$ & 0.582 \\
\hline Peak VE (\% MVV) & $36 \pm 13$ & $38 \pm 15$ & 0.249 \\
\hline Peak HR (BPM) & $86 \pm 13$ & $83 \pm 11$ & 0.284 \\
\hline Peak HR (\% CPET) & $72 \pm 13$ & $71 \pm 11$ & 0.374 \\
\hline Borg dyspnoea (Points) & $2 \pm 1$ & $2 \pm 1$ & 0.154 \\
\hline Borg fatigue (Points) & $2 \pm 2$ & $2 \pm 1$ & 0.680 \\
\hline
\end{tabular}

The data are presented as mean \pm SD before and after a single session of low-frequency neuromuscular electrical stimulation (LF-NMES) versus high-frequency neuromuscular electrical stimulation (HF-NMES) in 17 COPD patients.

$V O_{2}$ oxygen uptake in $\mathrm{ml} / \mathrm{min}$, \% peak $\mathrm{VO}_{2}$ CPET oxygen uptake expressed as a proportion of the peak $\mathrm{VO}_{2}$ obtained at the end of a symptomlimited cardiopulmonary exercise test, peak $V E$ peak minute ventilation in 1, \% $M V V$ percentage maximal voluntary ventilation $\left(\mathrm{MVV}=40 \times \mathrm{FEV}_{1}\right)$

COPD who are severely disabled by their dyspnea. In fact, mean peak oxygen uptake, ventilation, and heart rate were well below maximum values during a session of LF-NMES and comparable to the values during a session of HF-NMES (Table 2).

Oxygen uptake, ventilation, and symptoms during a session of HF-NMES in the present study corroborate previous results of our group [15]. Yet again, these findings show that COPD patients use a clearly lower proportion of their peak aerobic capacity during a session of NMES compared to a session of high-intensity lower-limb resistance training [15], treadmill walking, or stationary cycling [14]. Indeed, the biphasic current used during the HF-NMES and the LF-NMES was well tolerated by the patients (e.g., no drop out from the protocol and no adverse events) and led to acceptable levels of dyspnea and fatigue in COPD (Table 2).

This pilot study had some methodological limitations and selected patient characteristics that may limit the external validity and broad applicability of the present findings. Only patients without long-term oxygen therapy were eligible to participate due to the methodology used [14]. This study included a small number of COPD patients with a wide range of disease severity and different levels of physical function. Some of the participants may not be the typical patient who receives NMES in daily clinical practice. Indeed, NMES can be particularly useful for severely disabled patients with COPD [29].

Moreover, oxygen uptake and ventilation was evaluated during only a single session of LF-NMES and HF-NMES. Therefore, it is not possible to draw conclusions regarding the relative values of oxygen uptake and ventilation over longer periods of training or to identify subpopulations of patients who may benefit from either technique.
Session time, duty cycle, and pulse duration differed between both NMES protocols. This was due to the preset protocols of the commercially available NMES device. Nevertheless, the impact of these NMES features on the primary outcome (i.e., oxygen uptake) is expected to be nil.

Finally, magnetic stimulation can also be used as a nonvoluntary lower-limb muscle training method in patients with COPD [34]. However, magnetic stimulation is rather expensive and its clinical applicability in groups of COPD patients in clinical routine seems challenging.

In conclusion, oxygen uptake, ventilation, and symptom perception of dyspnea and leg fatigue were sustainably low and comparable during a single session of LF-NMES and HF-NMES in patients with COPD. These pilot findings provide an additional rationale to design randomized controlled trials to compare the effects of LF-NMES and HF-NMES on lower-limb dysfunction in (severely) disabled patients with COPD.

Acknowledgments The authors are grateful to the patients who graciously consented to participate in our study. This research was supported by research grants from the Netherlands Asthma Foundation, Leusden, the Netherlands (grant No. 3.4.09.024) and the Weijerhorst Foundation, Maastricht, the Netherlands.

Conflict of interest The authors have no conflicts of interest or financial ties to disclose.

\section{References}

1. Coronell C, Orozco-Levi M, Mendez R, Ramirez-Sarmiento A, Galdiz JB, Gea J (2004) Relevance of assessing quadriceps endurance in patients with COPD. Eur Respir J 24(1):129-136 
2. Seymour JM, Spruit MA, Hopkinson NS, Natanek SA, Man WD, Jackson A, Gosker HR, Schols AM, Moxham J, Polkey MI, Wouters EF (2010) The prevalence of quadriceps weakness in COPD and the relationship with disease severity. Eur Respir $\mathbf{J}$ 36(1):81-88

3. Franssen FM, Broekhuizen R, Janssen PP, Wouters EF, Schols AM (2005) Limb muscle dysfunction in COPD: effects of muscle wasting and exercise training. Med Sci Sports Exerc 37(1):2-9

4. Decramer M, Gosselink R, Troosters T, Verschueren M, Evers G (1997) Muscle weakness is related to utilization of health care resources in COPD patients. Eur Respir J 10(2):417-423

5. Gosselink R, Troosters T, Decramer M (1996) Peripheral muscle weakness contributes to exercise limitation in COPD. Am J Respir Crit Care Med 153(3):976-980

6. Swallow EB, Reyes D, Hopkinson NS, Man WD, Porcher R, Cetti EJ, Moore AJ, Moxham J, Polkey MI (2007) Quadriceps strength predicts mortality in patients with moderate to severe chronic obstructive pulmonary disease. Thorax 62(2):115-120

7. ATS/ERS (1999) Skeletal muscle dysfunction in chronic obstructive pulmonary disease. A statement of the American Thoracic Society and European Respiratory Society. Am J Respir Crit Care Med 159(4 Pt 2):S1-S40

8. Nici L, Donner C, Wouters E, Zuwallack R, Ambrosino N, Bourbeau J, Carone M, Celli B, Engelen M, Fahy B, Garvey C, Goldstein R, Gosselink R, Lareau S, MacIntyre N, Maltais F, Morgan M, O'Donnell D, Prefault C, Reardon J, Rochester C, Schols A, Singh S, Troosters T, ATS/ERS Pulmonary Rehabilitation Writing Committee (2006) American Thoracic Society/ European Respiratory Society statement on pulmonary rehabilitation. Am J Respir Crit Care Med 173(12):1390-1413

9. Spruit MA, Vanderhoven-Augustin I, Janssen PP, Wouters EF (2008) Integration of pulmonary rehabilitation in COPD. Lancet 371(9606): 12-13

10. Lacasse Y, Goldstein R, Lasserson TJ, Martin S (2006) Pulmonary rehabilitation for chronic obstructive pulmonary disease. Cochrane Database Syst Rev 2006(4):CD003793

11. Spruit MA, Gosselink R, Troosters T, De Paepe K, Decramer M (2002) Resistance versus endurance training in patients with COPD and peripheral muscle weakness. Eur Respir J 19(6): 1072-1078

12. Beauchamp MK, Dolmage TE, Nonoyama M, Goldstein RS, Hill K, Mathur S, Brooks D (2010) Interval versus continuous training in individuals with COPD—a systematic review. Thorax 65(2): 157-164

13. Spruit MA, Wouters EF (2007) New modalities of pulmonary rehabilitation in patients with chronic obstructive pulmonary disease. Sports Med 37(6):501-518

14. Probst VS, Troosters T, Pitta F, Decramer M, Gosselink R (2006) Cardiopulmonary stress during exercise training in patients with COPD. Eur Respir J 27(6):1110-1118

15. Sillen MJ, Janssen PP, Akkermans MA, Wouters EF, Spruit MA (2008) The metabolic response during resistance training and neuromuscular electrical stimulation (NMES) in patients with COPD, a pilot study. Respir Med 102(5):786-789

16. Vanderthommen M, Crielaard JM (2001) Muscle electric stimulation in sports medicine. Rev Med Liege 56(5):391-395

17. Vivodtzev I, Lacasse Y, Maltais F (2008) Neuromuscular electrical stimulation of the lower limbs in patients with chronic obstructive pulmonary disease. J Cardiopulm Rehabil Prev 28(2):79-91

18. Nuhr MJ, Pette D, Berger R, Quittan M, Crevenna R, Huelsman M, Wiesinger GF, Moser P, Fialka-Moser V, Pacher R (2004) Beneficial effects of chronic low-frequency stimulation of thigh muscles in patients with advanced chronic heart failure. Eur Heart J 25(2):136-143
19. Quittan M, Wiesinger GF, Sturm B, Puig S, Mayr W, Sochor A, Paternostro T, Resch KL, Pacher R, Fialka-Moser V (2001) Improvement of thigh muscles by neuromuscular electrical stimulation in patients with refractory heart failure: a singleblind, randomized, controlled trial. Am J Phys Med Rehabil 80(3):206-214; quiz 215-216, 224

20. Gosker HR, Lencer NH, Franssen FM, van der Vusse GJ, Wouters EF, Schols AM (2003) Striking similarities in systemic factors contributing to decreased exercise capacity in patients with severe chronic heart failure or COPD. Chest 123(5):1416-1424

21. Gosker HR, Zeegers MP, Wouters EF, Schols AM (2007) Muscle fibre type shifting in the vastus lateralis of patients with COPD is associated with disease severity: a systematic review and metaanalysis. Thorax 62(11):944-949

22. Van't Hul A, Harlaar J, Gosselink R, Hollander P, Postmus P, Kwakkel G (2004) Quadriceps muscle endurance in patients with chronic obstructive pulmonary disease. Muscle Nerve 29(2): 267-274

23. Rabe KF, Hurd S, Anzueto A, Barnes PJ, Buist SA, Calverley P, Fukuchi Y, Jenkins C, Rodriguez-Roisin R, van Weel C, Zielinski J; Global Initiative for Chronic Obstructive Lung Disease (2007) Global strategy for the diagnosis, management, and prevention of chronic obstructive pulmonary disease: GOLD executive summary. Am J Respir Crit Care Med 176(6):532-555

24. Spruit MA, Pennings HJ, Janssen PP, Does JD, Scroyen S, Akkermans MA, Mostert R, Wouters EF (2007) Extra-pulmonary features in COPD patients entering rehabilitation after stratification for MRC dyspnea grade. Respir Med 101(12):2454-2463

25. Charlson ME, Pompei P, Ales KL, MacKenzie CR (1987) A new method of classifying prognostic comorbidity in longitudinal studies: development and validation. J Chronic Dis 40(5):373-383

26. Borg GA (1982) Psychophysical bases of perceived exertion. Med Sci Sports Exerc 14(5):377-381

27. Borges O (1989) Isometric and isokinetic knee extension and flexion torque in men and women aged 20-70. Scand J Rehabil Med 21(1):45-53

28. Troosters T, Gosselink R, Decramer M (1999) Six minute walking distance in healthy elderly subjects. Eur Respir J 14(2): 270-274

29. Sillen MJ, Speksnijder CM, Eterman RM, Janssen PP, Wagers SS, Wouters EF, Uszko-Lencer NH, Spruit MA (2009) Effects of neuromuscular electrical stimulation of muscles of ambulation in patients with chronic heart failure or COPD: a systematic review of the English-language literature. Chest 136(1):44-61

30. Roig M, Reid WD (2009) Electrical stimulation and peripheral muscle function in COPD: a systematic review. Respir Med 103(4):485-495

31. Neder JA, Sword D, Ward SA, Mackay E, Cochrane LM, Clark CJ (2002) Home-based neuromuscular electrical stimulation as a new rehabilitative strategy for severely disabled patients with chronic obstructive pulmonary disease (COPD). Thorax 57(4): 333-337

32. Vivodtzev I, Pepin JL, Vottero G, Mayer V, Porsin B, Levy P, Wuyam B (2006) Improvement in quadriceps strength and dyspnea in daily tasks after 1 month of electrical stimulation in severely deconditioned and malnourished COPD. Chest 129(6): $1540-1548$

33. Zanotti E, Felicetti G, Maini M, Fracchia C (2003) Peripheral muscle strength training in bed-bound patients with COPD receiving mechanical ventilation: effect of electrical stimulation. Chest 124(1):292-296

34. Bustamante V, López de Santa María E, Gorostiza A, Jiménez U, Gáldiz JB (2010) Muscle training with repetitive magnetic stimulation of the quadriceps in severe COPD patients. Respir Med 104(2):237-245 